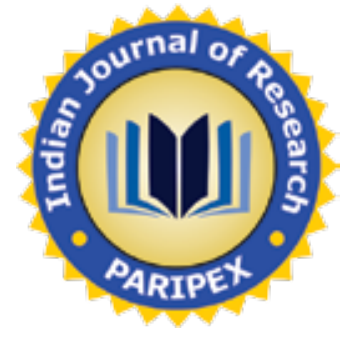

Veerabhadrappa.M

\title{
Family Influences on Adolescents' Peer Groups: Relations with Parents and Sibling Characteristics
}

\section{Research scholar, Department of Education, Bangalore University.} Karnataka.

\section{Dr. M. Narayanaswamy}

\section{Associate professor, Department of Education, Bangalore Univer-} sity. Karnataka

This exploratory study examines the influence of parents and siblings on adolescent peer group characteristics. Seventy-eight sibling dyads from six Bangalore high schools provided data used to explore the relationship between parental knowledge of events (parental monitoring), adolescent individual characteristics, sibling characteristics, and adolescent peer group characteristics. Results indicate that parental monitoring and sibling characteristics do predict adolescent and adolescents' peers' and substance use, however, it appears that familial influences on adolescent peer groups are mediated through adolescent characteristics. There is no evidence suggesting that older siblings are more influential than younger siblings or those same-sex sibling dyads are more similar than mixed-sex sibling dyads.

\section{KEYWORDS} peer group, parental monitoring, delinquency, sibling influence.

\section{Introduction}

It has been well documented that peer relationships are a central component of adolescent development. For the majority of children, adolescence marks a time of increased orientation towards peers and peer-related activities, with adolescents spending more than fifty percent of their waking hour with friends (Steinberg, 1993). For many adolescents, friendships are critical interpersonal bridges that move them towards psychological growth and maturity (Savin-Williams \& Berndt, 1990), allowing for social comparison, influencing the development of self-evaluation, social cognition, and ultimately social behavior (Rubin \& Stewart, 1996). However, it is through the peer group that adolescents are most likely to be introduced to problem behaviors such as drinking, smoking, and delinquency (McCord, 1990).

Although peer influence has often been conceptualized as undermining the influence of the family (i.e. Coleman, 1961), more recent research has begun to take a closer look at the relationship between family and peers, examining potential familial influences on peer group formation. In a series of studies examining the interrelationship of parenting, adolescent characteristics, and peer group characteristics, Steinberg and his colleagues have concluded that parental influence on peer group affiliation is mediated through the influence of parents on their own children, who then seek peers similar to themselves (Steinberg, Darling, and Fletcher, 1995).

In the current study, five specific hypotheses were formulated in an attempt to best describe the relation between child and familial characteristics and their influence on adolescent peer group characteristics. First, because previous research suggests that parents and siblings influence various child characteristics, it was hypothesized that parental monitoring and sibling characteristics would predict adolescent grade point average, work orientation, deviance, and substance use. Second, based on research suggesting significant differences in peer groups of adolescent males and females, it was hypothesized that samesex sibling dyads would have more similar peer groups than would mixed-sex sibling dyads. Third, based on past research suggesting parents influence both child characteristics and social context, it was hypothesized that parental monitoring would predict adolescent peer group characteristics. Fourth, based on past research indicating significant sibling influences on various child outcomes, it was hypothesized that sibling characteristics would also predict adolescent peer group characteristics. Finally, because adolescents are often introduced into deviance through older peers, it was hypothesized that overlap among sibling peer groups would be substantial and that older siblings would predict the peer group characteristics of their younger siblings to a greater extent than younger siblings would predict peer group affiliation of their older brothers and sisters.

\section{Methods \\ Sample}

The data for the current study came from two self-report questionnaires administered 9th-10th graders attending Bangalore high schools selected to provide an ethnically and socioeconomically mixed sample of urban and rural families. Sibling dyads were identified by matching the addresses and names of respondents.

\section{Procedure}

All students in participating schools were invited to complete a self-report questionnaire that focused on school-related behaviors (academic achievement, engagement in classes, extracurricular participation) but also included measures of family relationships and parenting behaviors, peer relationships, deviant activities, and psychological well-being. Because of its length, the questionnaire was divided into two sections, each administered on separate days. Students also received peer ratings of crowd affiliation, based on the Social Type Rating (STR) procedure (Brown 1989).

\section{Measures}

The questionnaires contained a variety of information regarding adolescent family background, psychosocial functioning, family and peer relations, schooling, extracurricular participation, and problem behavior. The current study is specifically interested in measures of parental attempts at monitoring and actual levels of parental monitoring (parental knowledge of events), as well as various externalizing outcomes (school performance, work orientation, deviance, and substance use) for adolescents, siblings, and peers. Peer information was obtained in the following manner: adolescents were first asked to name their 5 closest friends from school. Because the majority of peers named attended the same schools as the target adolescents, often times peers were also participants in the study. Hence, information could be obtained about their 
academic achievement, work orientation, deviance, and substance use from completed questionnaires. Peer group characteristics were measured by averaging these characteristics across the 5 peers named. Addresses and last names were used to identify approximately 40 co-residing sibling dyads with complete information on peer group affiliation.

\section{Results:}

Correlations were calculated to assess the similarity of siblings on their perception of parents, their academic/work orientation, academic achievement, substance use and delinquency, and the characteristics of their peer groups. Results are reported in Table 1.

Table 1. Correlations between siblings' individual characteristics, peer group characteristics, and perceptions of parents

\begin{tabular}{|c|c|c|}
\hline & $R$ & $\mathrm{~N}$ \\
\hline \multicolumn{3}{|l|}{ Perception of parents: } \\
\hline Parental monitoring attempt & $.34 * *$ & 77 \\
\hline Pareb=ntal knowledge of events & .11 & 78 \\
\hline \multicolumn{3}{|l|}{ Child characteristics } \\
\hline Academic achievement & $.27 *$ & 76 \\
\hline Work orientation & -0.8 & 44 \\
\hline Delinquency & .18 & 56 \\
\hline Substance use & $.49 * *$ & 52 \\
\hline \multicolumn{3}{|l|}{ Peer group characteristics } \\
\hline Academic achievement & .31 & 38 \\
\hline Work orientation & .27 & 37 \\
\hline Delinquency & .01 & 37 \\
\hline Substance use & $.78 * *$ & 37 \\
\hline
\end{tabular}

To test the difference between same-sex and mixed-sex sibling dyads, simple correlations on all outcome variables were computed separately for same-sex and mixed-sex dyads. Multiple regression models were used to test the differences between the two sets of correlations. Results are presented in table 2

Table 2. Correlations and tests of significant differences between same-sex and mixed-sex sibling dyads in regards to their individual characteristics, peer group characteristics, and perceptions of parents.

\begin{tabular}{|l|l|l|l|l|l|l|}
\hline & \multicolumn{3}{|l|}{$\begin{array}{l}\text { Same-Sex } \\
\text { Dyads }\end{array}$} & \multicolumn{2}{l|}{$\begin{array}{l}\text { Mixed-Sex } \\
\text { Dyads }\end{array}$} & \\
\hline $\begin{array}{l}\text { Perceptions of } \\
\text { Parents }\end{array}$ & $\underline{R}$ & $(n)$ & $R$ & $(n)$ & Difference \\
\hline $\begin{array}{l}\text { parental monitoring } \\
\text { attempts }\end{array}$ & $.38^{*}$ & $(45)$ & .28 & $(32)$ & - \\
\hline $\begin{array}{l}\text { parental knowledge } \\
\text { of events }\end{array}$ & .05 & $(45)$ & .18 & $(33)$ & - \\
\hline
\end{tabular}

\section{Child Characteristics}

academic

achievement (GPA)

\begin{tabular}{l|}
$.43 * *$ \\
-.07 \\
.11 \\
.42
\end{tabular}

(45)

work orientation

delinquency

substance use

\begin{tabular}{l|l|l|l|l}
.42 & $(31)$ & $.60 * *$ & $(21)$ & -
\end{tabular}

Peer Characteristics

\begin{tabular}{|l|l|l|l|l|l|}
\hline $\begin{array}{l}\text { academic } \\
\text { achievement (GPA) }\end{array}$ & .27 & $(23)$ & .37 & $(15)$ & - \\
\hline work orientation & -.01 & $(23)$ & $.65^{*}$ & $(14)$ & $*$ \\
\hline delinquency & -.22 & $(23)$ & .15 & $(14)$ & - \\
\hline substance use & $.59 *$ & $(14)$ & $.82 * *$ & $(23)$ & - \\
\hline$\# \mathrm{p}<.10 ;{ }^{*} \mathrm{p}<.05 ;{ }^{* *} \mathrm{p}<.01$ \\
\hline
\end{tabular}

As shown in table 2, same and mixed-sex dyads did not differ in the similarity with which they perceived parents. A near significant difference between same-sex and mixed-sex siblings' levels of academic achievement suggests that grade point averages of same-sex sibling dyads are more similar than are grade point averages of mixed-sex sibling dyads. Contrary to our hypothesis, peers of same-sex sibling dyads were no more similar than peers of same-sex dyads, differing only in terms of their academic/work orientation.

Multiple regression analyses were used to examine the influence of parents and siblings on adolescents. Because previous research has suggested that it is more likely that younger siblings are influenced by older siblings than vice versa, separate analyses were performed predicting younger sibling characteristics from older siblings, and older siblings from younger. Results are reported in table 3 .

Table 3. Standardized regression coefficients of adolescent characteristics being predicted by parental monitoring and sibling characteristics.

\begin{tabular}{|l|l|l|l|}
\hline & $\begin{array}{l}\text { Parental } \\
\text { Knowledge }\end{array}$ & $\begin{array}{l}\text { Sibling } \\
\text { Characteristic }\end{array}$ & $\begin{array}{l}\text { Multiple } \\
\text { R }\end{array}$ \\
\hline \multicolumn{3}{|l|}{ Younger siblings predicted by older siblings } \\
\hline $\begin{array}{l}\text { academic achievement } \\
\text { (GPA) }\end{array}$ & -.02 & .27 & .27 \\
\hline work orientation & -.02 & -.06 & .07 \\
\hline delinquency & $-.27 \#$ & .12 & .31 \\
\hline substance use & -.08 & $.60 * *$ & .61 \\
\hline Older siblings predicted by younger siblings & \\
\hline $\begin{array}{l}\text { academic achievement } \\
\text { (GPA) }\end{array}$ & -.16 & $.29 *$ & .31 \\
\hline work orientation & .25 & -.15 & .27 \\
\hline delinquency & $-.31 *$ & .15 & .33 \\
\hline substance use & $-.27 \#$ & $.33^{*}$ & .43 \\
\hline$\# p<.10 ;{ }^{*} p<.05 ; * \star p<.01$ \\
\hline
\end{tabular}

Results indicate that siblings' substance use predicts adolescent substance use, even controlling for parental knowledge. This holds true for both younger and older siblings. Younger siblings' academic achievement also predicts the academic achievement of older siblings, controlling for parental knowledge.

When parent, child, and sibling characteristics were used to predict the characteristics of adolescent peer groups, the relationship of both parental knowledge and sibling characteristics with peer substance use dropped below significance (see Table 4). These results suggest that the similarity of siblings' peers in terms of substance use is mediated through the similarity of the siblings themselves, rather than the product of direct influence.

Table 4. Standardized regression coefficients of adolescent peer group characteristics being predicted by parental monitoring, sibling characteristics, and child characteristics

\begin{tabular}{|c|c|c|c|c|}
\hline & \begin{tabular}{|l|} 
Parents' \\
Knowledge
\end{tabular} & \begin{tabular}{|l} 
Sibling \\
Charac- \\
teristics
\end{tabular} & $\begin{array}{l}\text { Child Char- } \\
\text { acteristics }\end{array}$ & $\mathrm{R}_{\mathrm{R}}^{\text {Multiple }}$ \\
\hline \multicolumn{5}{|c|}{ Younger Siblings } \\
\hline $\begin{array}{l}\text { academic } \\
\text { achievement } \\
\text { (GPA) }\end{array}$ & -.01 & .11 & $.38 *$ & .41 \\
\hline $\begin{array}{l}\text { work } \\
\text { orientation }\end{array}$ & -.04 & -.03 & .17 & .19 \\
\hline delinquency & .16 & -.03 & .03 & .15 \\
\hline substance use & -.02 & -.11 & $.71 * *$ & .64 \\
\hline
\end{tabular}




\begin{tabular}{|l|l|l|l|l|}
\hline $\begin{array}{l}\text { academic } \\
\text { achievement } \\
\text { (GPA) }\end{array}$ & -.09 & .04 & $.29 \#$ & .32 \\
\hline $\begin{array}{l}\text { work } \\
\text { orientation }\end{array}$ & .11 & -.04 & .15 & .21 \\
\hline delinquency & .16 & $.28 \#$ & .08 & .33 \\
\hline substance use & .05 & -.11 & $.48^{*}$ & .42 \\
\hline
\end{tabular}

$\# p<.10 ;{ }^{*} p<.05 ; * * p<.01$

\section{Discussion}

The present study was designed to explore the relationship between familial influences and adolescent peer group characteristics. In support of our first hypothesis, results indicate that both parents and sibling characteristics predict adolescent characteristics. In fact, contrary to previous suggestions, sibling influences are not specific to various externalizing outcomes such as substance use and delinquency; rather, siblings appear to have a strong influence on levels of adolescent academic achievement as well. In addition, the more parents' know about an adolescent's activities, the less likely the adolescent is to engage in delinquent activities. Contrary to previous research suggesting differential familial influences on older and younger siblings, our data suggest both parental monitoring and sibling characteristics were equally predictive of younger and older adolescent characteristics.

Contrary to our second hypothesis, peers of same-sex sibling dyads are no more similar than peers of mixed-sex sibling dyads; these groups differed only in terms of work orientation. In fact, examination of the magnitude of both significant and non-significant correlations suggests that although same-sex dyads perceive their parents as more similar than do mixed-sex dyads and same-sex dyads tend to be more similar in terms of academics, mixed-sex dyads may be more similar to one another in terms of delinquency and substance use. If these results were replicated, it might support the idea that siblings who are similar to one another try to distinguish between themselves by exaggerating their differences (Dunn \& Plomin 1991). The observed lack of difference between same and mixed-sex siblings might also be due to the outcome variables used for comparison and the developmental age of the subjects participating in the study. Because adolescence is a time of experimentation with various activities including delinquency and substance use, we may expect differences between the sexes to be less pronounced during these times, as compared to other developmental periods (e.g., pre-adolescence or even late adolescence). In fact, those "non-externalizing" outcomes (i.e. academic achievement and academic/work orientation) are the outcomes where differences between the adolescents and peers of same-sex and mixed-sex sibling dyads are observed.

Contrary to our third and fourth hypotheses, neither parents nor siblings independently predict adolescent peer group orientation for either older or younger siblings. One possible explanation for this finding is that child characteristics mediate the association between parenting monitoring and peer group affiliation, as well as the relationship between sibling characteristics and peer group affiliation. Instead of directly influencing peers, parental monitoring and sibling characteristics may directly influence adolescent grade point average, academic/work orientation, substance use, delinquency, which may then directly influence peer group affiliation. The results of the present study partially support this notion. As is evident in table 3, both older and younger sibling characteristics significantly predict adolescent levels of academic achievement and substance use. From table 4 we can see, in fact, that adolescent levels of academic achievement and substance use are significant predictors of these same qualities in their respective peer groups.

Although the present study provides us with a variety of information regarding familial influences on the type of peers with whom adolescents' affiliate, further research is clearly needed. First, because the current study was exploratory, small sample sizes limited the power of our design and hindered our ability to produce a greater number of significant results. Future studies with larger samples of sibling dyads and peer networks are needed to obtain an accurate representation of familial influences on adolescent peer group formation. Second, because the current study was a pilot study, single variables of parenting were chosen to represent typical parenting practices. Future studies must use an array of parenting measures to accurately obtain a measure of parenting style. Third, although the current study suggests that parents and siblings provide a direct influence on adolescent outcomes, we do not know how this influence occurs, or whether it occurs differently for parental and sibling influences. Hence, future research must consider the process by which familial influences occur. Fourth, based on the results of the present study suggesting a mediational influence of child characteristics on the relationship of familial influence and outcome, further research is needed to test for mediational influences. Finally, as a complement to the externalizing outcomes used in the previous study, future research is need to determine if familial influences generalize to more internalizing outcomes such as self-esteem and self-worth.

The present study suggests that siblings are an important component necessary to understanding the links between families and peers. As such, they provide a key to understanding how and why the peer groups that adolescents affiliate with complement, rather than undermine, the influence of families.

\section{REFERENCES}

Bandura, A. (1977). Social learning theory. Englewood Cliffs, NJ: Prentice Hall. | Brown, B. B. (1989). Social Type Rating Manual. Madison, WI: National Center on Effective Secondary Schools, University of Wisconsin-Madison. | Brown, B. B. (1990). Peer groups and peer cultures. In S. S. Feldman \& G. R. Elliot (Eds.), At The Threshold (pp. 171196). Cambridge, MA: Harvard University Press. | Brown, B. B., Mounts, N., Lamborn, S. D., \& Steinberg, L. (1993). Parenting practices and peer group affiliation in adolescence. Child Development, 64, 467-482. | Coleman, J. S. (1961). The adolescent society. In S. S. Feldman \& G. R. Elliot (Eds.), At The Threshold (pp. 278-279). Cambridge, MA: Harvard University Press. | Durbin, D. L., Darling, N., \& Brown, B. B. (1993). Parenting style and peer group membership among European-American adolescents. Journal of Research on Adolescence, 3(1), 87-100. | Minnet, A. M., Vandell, D. L., \& Santrock, J. W. (1983). The effects of sibling status on sibling interaction: Influence of birth order, age spacing, sex of child, and sex of sibling. Child Development, 54, 1064-1072. | Rubin, K. H., \& Stewart, S. L. (1996). Social withdrawal. In E. J. Mash \& R.A. Barkley (Eds.), Child Psychopathology (pp. 277-307). Cambridge, MA: Harvard University Press. | Savin-Williams, R. C., \& Berndt, T. J. (1990). Friendship and peer relations. In S. S. Feldman \& G. R. Elliot (Eds.), At The Threshold (pp. 277-307). Cambridge, MA: Harvard University Press. | Steinberg, L. (1993). Adolescence. New York: McGraw-Hill. | Steinberg, L., Darling, N., Fletcher, A. C., Brown, B. B., \& Dornbusch, S. M. (1995). Authoritative parenting and adolescent adjustment: An ecological journey. In P. Moen, G. Elder, \& K. Luscher (Eds.), Examining Lives In Context (pp. 423-466). Washington, DC: American Psychological Association. | 